\section{Mixed model-based Jinks and Pooni method to predict segregating populations in wheat breeding}

\section{Henrique Caletti Mezzomo ${ }^{1^{*}}$, Cleiton Renato Casagrande ${ }^{1}$, Diana Jhulia Palheta de Sousa ${ }^{1}$, Aluízio Borém ${ }^{1}$, Fabyano Fonseca e Silva ${ }^{2}$ and Maicon Nardino ${ }^{1}$}

\begin{abstract}
The improvement of superior wheat cultivars depends on the identification of promising segregating populations to derive superior lines. A lattice model (8×8) involving $56 F_{2}$ populations and eight parents was conducted in the 2020 cropping season, and grain yield per plant was evaluated for every $F_{2}$ population, with further analysis of the population potential by Jinks and Pooni method via REML/BLUP. A total of $5,410 \mathrm{~F}_{2}$ plants were evaluated in this study. The results showed that the use of genetic variance associated with the individual genotypic value (BLUP) was superior compared with the use of variance and traditional phenotypic values. The $F_{2}$ populations, CD 1303/BRS 254, CD 1303/Tbio Duque, CD 1303/Tbio Ponteiro, BRS 264/Tbio Aton, Tbio Ponteiro/Tbio Aton, and Tbio Sossego/CD 1303 had the highest likelihood of deriving superior lines.
\end{abstract}

Keywords: Triticum aestivum L; quantitative genetics; plant selection

\section{INTRODUCTION}

Brazil has a wheat deficit of approximately six million tons (CONAB 2021). However, the country has the potential to expand its wheat production, especially in the Brazilian Cerrado region (Pasinato et al. 2018); hence, cultivars adapted to the climatic conditions of that region need to be developed (Pereira et al. 2019).

One of the challenges of breeding programs is the formation of segregating populations with the potential to derive superior lines since they depend on the concentration of favorable alleles in the parents involved (Fasahat et al. 2016) and on the early evaluation of the populations obtained, which allows selection of those with potential and discarding the least promising populations, saving time and resources from the breeding program. The method by Jinks and Pooni (1976) is a possible tool for evaluating the potential of segregating populations in early generations in soy (Lima et al. 2012), beans (Rocha et al. 2013), and rice (Morais Júnior et al. 2015).

However, one of the challenges of the method proposed by Jinks and Pooni (1976) is that it estimates variances based on the evaluation of individual plants, which can culminate in negative variance estimates (Pimentel et al. 2013). Considering this problem, the restricted maximum likelihood (REML) method can be an alternative to the least-squares method. For variance component estimates, the REML method is translation-invariant; it does not provide
Crop Breeding and Applied Biotechnology 21(4): e38352143, 2021 Brazilian Society of Plant Breeding. Printed in Brazil http://dx.doi.org/10.1590/198470332021v21n4a52

\footnotetext{
*Corresponding author: E-mail:hc_mezzomo@hotmail.com (iD) ORCID: 0000-0002-8220-9611
}

Received: 01 June 2021 Accepted: 08 September 2021 Published: 20 November 2021

\footnotetext{
${ }^{1}$ Universidade Federal de Viçosa, Departamento de Agronomia, Avenida Peter Henry Rolfs, s/n, 36570-900, Viçosa, MG, Brazil ${ }^{2}$ Universidade Federal de Viçosa, Departamento de Zootecnia, Avenida Peter Henry Rolfs, s/n, 36570-000, Viçosa, MG, Brazil
} 
variance component estimates outside the parametric space and does not provide biased estimates. Additionally, the best linear unbiased prediction (BLUP) method provides the genotypic value of individual plants even under unbalanced conditions, based on the mean performance of the population and their respective parents (Resende and Alves 2020).

In that context, the REML/BLUP method has been extensively used in studies of quantitative genetics (Silva et al. 2013), genetic diversity (Casagrande et al. 2020), and diallel analysis (Laviola et al. 2018), as well as the method by Jinks and Pooni (Morais Júnior 2014). However, the analysis and selection of promising segregating wheat populations using the variance components of REML and the genetic effects of BLUP using the methodology by Jinks and Pooni (1976) to derive superior lines has not been documented.

Therefore, the objectives of this study were to evaluate the genetic potential of 56 tropical wheat $F_{2}$ populations in 5,410 plants, derive superior lines, and select plants with superior performance through the method by Jinks and Pooni (1976) via REML/BLUP.

\section{MATERIAL AND METHODS}

\section{Crossing of $F_{1}$ populations}

To obtain the experimental material, eight tropical wheat cultivars were crossed in a complete diallel crossing scheme. Cultivars from three different breeding programs were selected for good agronomic performance variables, including grain yield, health, and plant architecture, combined with quality traits of wheat such as gluten strength, in addition to being adaptable to cultivation in the Brazilian Cerrado region. The cultivars used were: CD 1303 (Cooperativa Central de Pesquisa Agrícola-COODETEC), BRS 254, BRS 264, and BRS 394 (Empresa Brasileira de Pesquisa Agropecuária - EMBRAPA), and four cultivars from Biotrigo Genética (Tbio Aton, Tbio Duque, Tbio Ponteiro, and Tbio Sossego). Hybridization was conducted between August and October 2019. In February 2020, $F_{1}$ seeds obtained from each crossing were multiplied to generate the $F_{2}$ populations. Both activities were conducted in the greenhouse at the Department of Agronomy at the Federal University of Viçosa, Minas Gerais State, Brazil.

\section{Field experiment}

A total of 5,410 $\mathrm{F}_{2}$ plants were evaluated in the field during the 2020 winter cropping season, in the field at the Department of Agronomy of the Federal University of Viçosa (lat 20 45' 14" S, long 42 52' 55" W, and altitude of 648 $\mathrm{m})$, Viçosa, Minas Gerais State, Brazil. The $56 \mathrm{~F}_{2}$ combinations and 8 parents were evaluated in the field using a lattice model $(8 \times 8)$ with 2 replicates. The experimental plot consisted of three rows of $3 \mathrm{~m}$ with an intra-row spacing of 0.2 $\mathrm{m}$. Ten seeds were sown per meter following the pedigree method by McVetty and Evans (1980). In each plot, individual plants were harvested, threshed, and the grain yield per plant $\left(\mathrm{g} \mathrm{pl}^{-1}\right)$ was determined.

The experiment was conducted under sprinkler irrigation. Basic and cover fertilization were applied for soil correction based on soil chemical analyses and according to the crop's nutritional needs. Control of weeds, insects, and pests was done using chemicals according to the recommendations for wheat cultivation in Brazil (Embrapa 2020).

\section{Statistical analysis}

Initially, the 56 density plots were evaluated using the phenotypic data and considering each $\mathrm{F}_{2}$ hybrid population to visualize the distribution behavior of the trait on grain yield per plant. The following statistical parameters were calculated from the data: number of observations (number of $\mathrm{pl}$, count); maximum, minimum, and mean value in $\mathrm{g} \mathrm{pl}^{-1}$; standard deviation (SD); coefficient of skewness according to Bowley (1920) (SK); and kurtosis (K).

The data for individual plants from the 56 populations and 8 parents were submitted to mixed model analysis to estimate genetic parameters via restricted maximum likelihood (REML) and predict genotypic values through the best linear unbiased prediction (BLUP). Initially, the following model was used to estimate the parameters for each population:

$$
y=X B+Z_{1} \mu_{1}+Z_{2} \mu_{2}+e_{1}
$$

where $y$ is the vector of the phenotypic data observed, $X$ and $B$ are the incidence matrix and the corresponding vector of fixed effects, respectively (general mean of the crossing in each sub-block), $Z_{1}$ and $Z_{2}$ are the matrices of random effects, $\mu_{1}$ is the vector of random effects of crossing $\mu_{1} \sim N\left(0, l \sigma_{\mu_{1}}^{2}\right), \mu_{2}$ is the vector of random effects of the plot $\mu_{2} \sim$ 
$N\left(0, I \sigma_{\mu_{2}}^{2}\right)$, and $e_{1}$ is the vector of residual random effects $e \sim N\left(0, I \sigma_{\mathrm{e}}^{2}\right)$.

Subsequently, the following model was used to fit the parents:

$$
y=X B+Z_{3} \mu_{3}+Z_{4} \mu_{4}+e_{2}
$$

where $y$ is the vector of phenotypic data of the parents, $B$ is the fixed effect vector of the general mean of the parents in each sub-block, $\mu_{3}$ is the vector of random genetic effects of the parents $\mu_{3} \sim N\left(0, l \sigma_{\mu 3}^{2}\right) \mu_{4}$ is the vector of random effects of the plot $\mu_{4} \sim N\left(0, I \sigma_{\mu 4}^{2}\right)$, and $e_{2}$ is the vector of residual random effects $e \sim N\left(0, I \sigma_{\mathrm{e}}^{2}\right)$. The terms $\mathrm{X}, \mathrm{Z}_{3}$, and $\mathrm{Z}_{4}$ constitute the incidence matrices of the aforementioned effects.

Finally, the individual genetic values of plants (BLUP) were obtained using the following model:

$$
y=X B+Z_{5} \mu_{5}+Z_{6} \mu_{6}+e_{3}
$$

where $y$ is the vector of the phenotypic data observed, $\beta$ is the vector of replicate effects (fixed), $\mu_{5}$ is the vector of the genotypic random effects of genotypes (populations and parents) $\mu_{5} \sim N\left(0, I \sigma_{\mu 5}^{2}\right), \mu_{6}$ is the vector of the plot random effects and $\mu_{6} \sim N\left(0, l \sigma_{\mu 6}^{2}\right)$, and $e_{3}$ is the vector of residual random effects $e \sim N\left(0, l \sigma_{\mathrm{e}}^{2}\right) . X, Z_{5}$ and $Z_{6}$ are the incidence matrices of the respective effects.

The mean genetic variance of the crossing $\left(\sigma_{\mu 1}^{2}\right)$ obtained by Model 1 is given by

$$
\hat{\sigma}_{\mu 1}^{2}=\left(1-F_{S T}\right) \hat{\sigma}_{a 0}^{2}
$$

where $F_{S T}$ is the inbreeding coefficient for the generation of populations, and $\hat{\sigma}_{a 0}^{2}$ is the original additive genetic variance of the parent population, given by $\hat{\sigma}_{a 0}^{2}=\hat{\sigma}_{p}^{2} / 2$, where $\hat{\sigma}_{p}^{2}$ is the genetic variance of the parents.

Heritability $\left(\hat{h}^{2}\right)$ was estimated by the following equation:

$$
\hat{h}^{2}=\hat{\sigma}_{\mu 1}^{2} / \hat{\sigma}_{e 1}^{2}
$$

where, $\hat{\sigma}_{e}^{2}$ is the residual variance.

After obtaining the variance and genotypic values (BLUPs), the probability of extracting line (P) from each population was estimated using the method by Jinks and Pooni (1976), with the probability corresponding to the direct area of a given value of $Z$ in the abscissa of the normal distribution. Then, measured through the $Z$ table that contains the probabilities $P(Z \geq Z)$ of the standard normal distribution, with $Z$ being obtained by:

$$
Z=\frac{\bar{L}-\bar{F}_{\mathrm{ni}}}{\sqrt{\hat{\sigma}_{g}^{2}}}
$$

where $\bar{L}$ corresponds to the standard genotypic value mean, corresponding to the mean grain yield per plant of the 56 $\mathrm{F}_{2}$ populations evaluated plus $1.5 \times \sigma_{g}$, that is, $12.14 \mathrm{~g} \mathrm{pl}^{-1}$, obtained through equation (3); $\sigma_{g}$ is the genotypic standard deviation of the $56 \mathrm{~F}_{2}$ populations obtained through equation $(3) ; \bar{F}_{n i}$ is the mean grain yield per plant estimated for each $F_{2}$ population, which corresponds to the mean of all possible lines in the $F_{\infty}$ generation in a model without dominance, as long as they are conducted without selection; and $\hat{\sigma}_{g}^{2}$ is the estimate of genetic variance between plants of the $F_{2}$ generation of each population individual, obtained through Equation (2).

In sequence, out of the $F_{2}$ populations that obtained a probability $(P)$ equal to or greater than $45 \%$, plants with a genotypic value higher than the mean of the populations previously selected were selected. Analyses were performed using the software Selegen (Resende 2016) and ggplot2 (Wickham 2016) package in the R (R Core Team 2020) environment.

\section{RESULTS AND DISCUSSION}

\section{Descriptive analysis}

The descriptive statistics of the 5,410 plants of the $F_{2}$ populations based on phenotypic data are shown in Table 1 . The number of plants evaluated ranged from 76 to 130, depending on the final stand of the plants at the end of the crop cycle. The highest yield $\left(35.33 \mathrm{~g} \mathrm{pl}^{-1}\right)$ was recorded in an $\mathrm{F}_{2}$ plant originating from the crossing of BRS 254/Tbio Ponteiro. The phenotypic mean of the $\mathrm{F}_{2}$ populations was $9.81 \mathrm{~g} \mathrm{pl}^{-1}$, which was higher than the $5.72 \mathrm{~g} \mathrm{pl}^{-1}$ reported by Pimentel et al. (2010) when measuring yield in individual $F_{3}$ plants of tropical wheat. 
Table 1. Descriptive analysis containing number of plants evaluated ( $\mathrm{n}$ o of pl), maximum (Max), minimum (Min) and mean phenotypic values, standard deviation (SD), skewness and kurtosis for the production per plant $\left(\mathrm{g} \mathrm{pl}^{-1}\right)$ of $56 \mathrm{~F}_{2}$ populations of tropical wheat

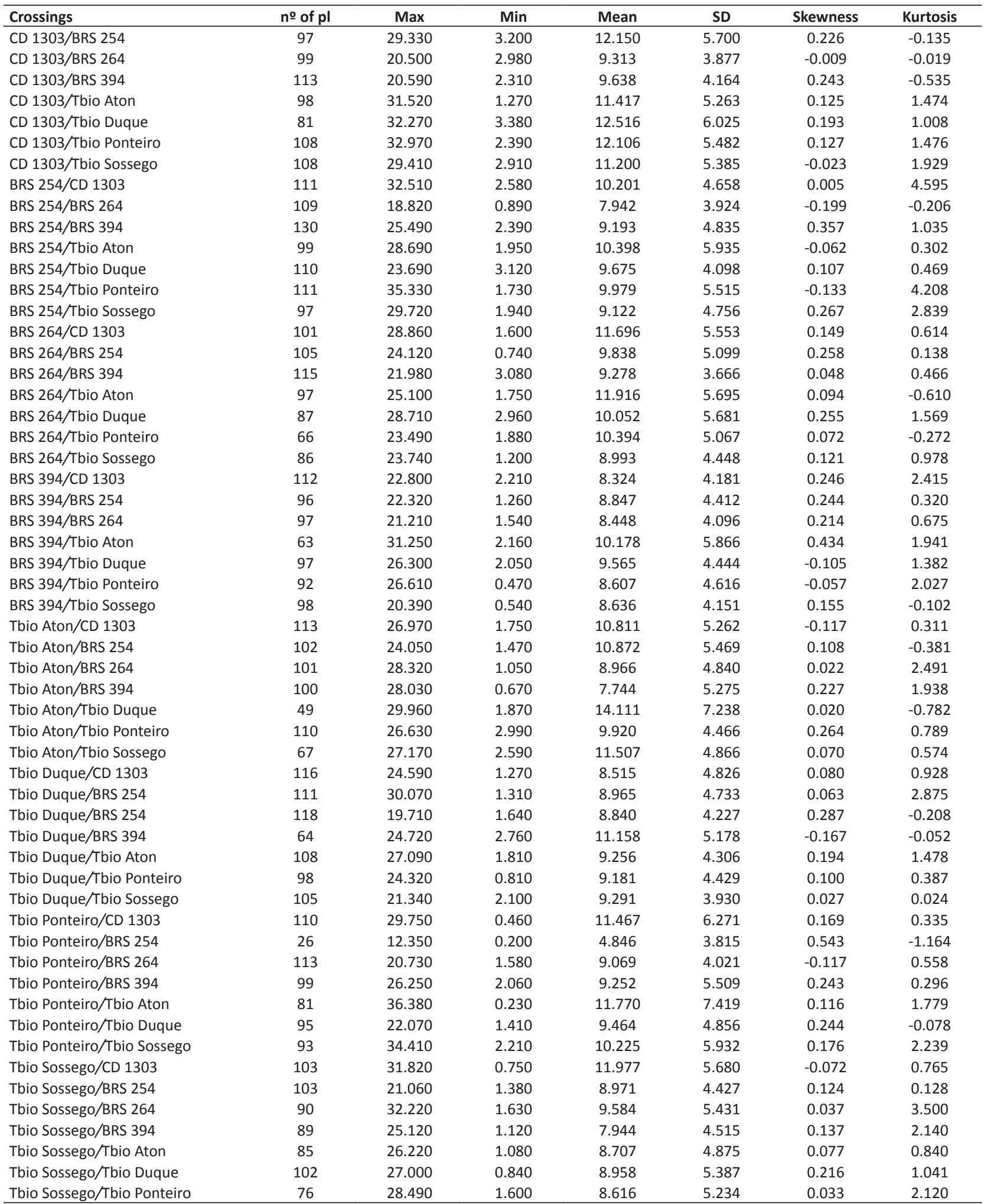


The phenotypic distribution patterns were verified for skewness and kurtosis (Table 1). $F_{2}$ populations showed almost normal patterns; the distributions showed weak skewness both on the right $(0<\mathrm{SK}<1)$ and left $(-1<\mathrm{SK}<0)$, although with stronger skewness to the right, that is, with a longer tail on the right, with values concentrated on the left of the mean. The highest skewness value on the right was observed in the BRS 394/Tbio Aton population (0.43). Most populations presented kurtosis characterized as platykurtic $(K<3)$, that is, the phenotypic data of the populations were less concentrated around the mean. Only the BRS 254/CD 1303, BRS 254/Tbio Ponteiro, and Tbio Sossego/BRS 264 presented leptokurtosis $(K>3)$. With the aim of genetic improvement, populations with asymmetric curves to the left (concentration of individuals above the average) were sought to increase the probability of deriving superior lines, highlighting populations with higher values of asymmetry on the left, including BRS 254/BRS264, BRS 254/Tbio Ponteiro, Tbio Aton/CD 1303, and Tbio Duque/BRS 394.

Based on Figure 1, it is possible to visualize the variability of the distribution patterns of $F_{2}$ populations of tropical wheat between the $F_{2}$ generations and their reciprocals. The visualized variability indicates that the distribution pattern

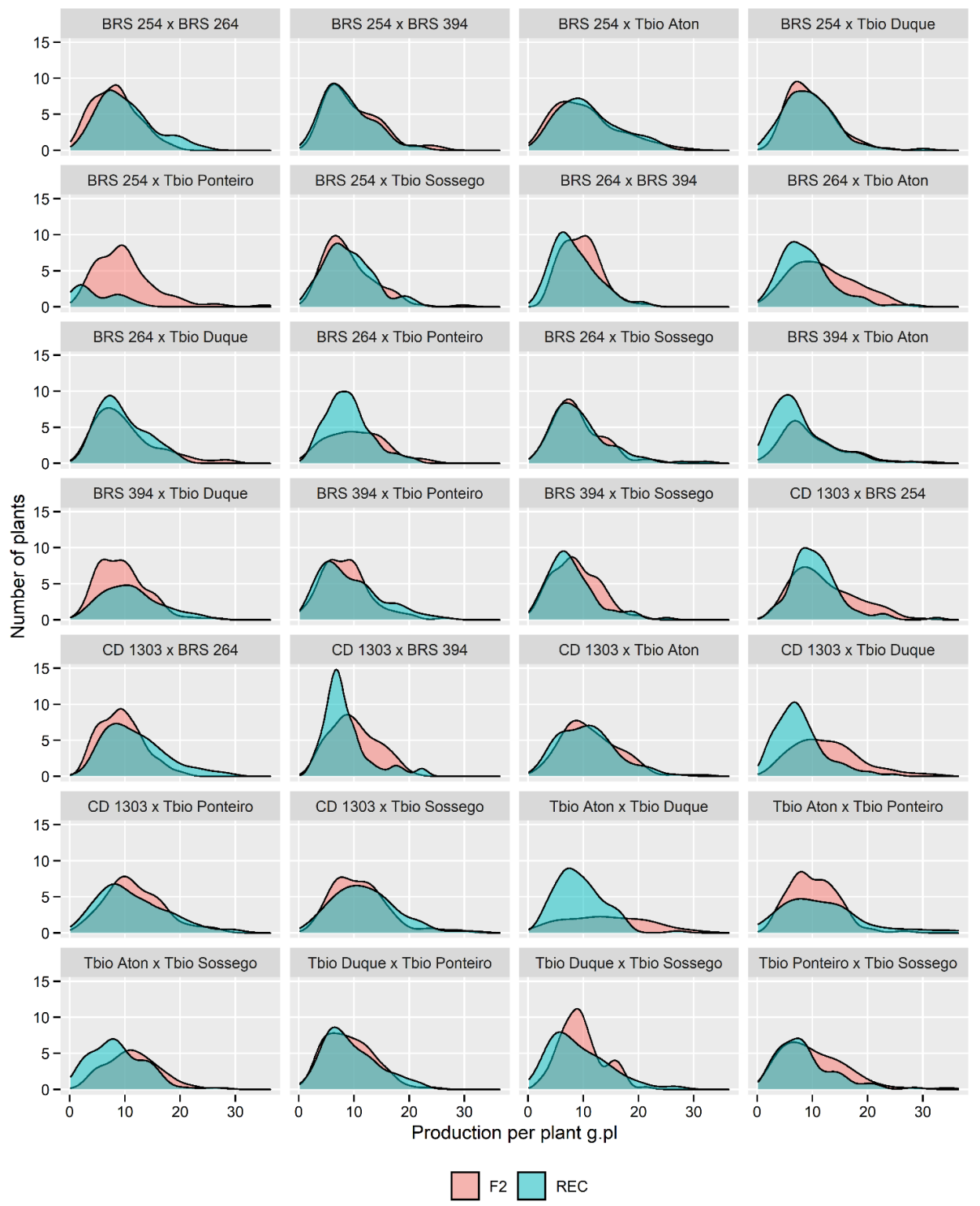

Figure 1. Pattern of density distribution of grain yield per plant in 56 tropical wheat $F_{2}$ populations. $F_{2}$ : crosses and REC: reciprocal. 
between $F_{2}$ populations and their respective reciprocals are similar, with greater visual discrepancies present in the BRS 254/Tbio Ponteiro, BRS 264/Tbio Aton, BRS 394/Tbio Duque, CD 1303/BRS 394, CD 1303/Tbio Duque, and Tbio Aton/ Tbio Ponteiro populations. Such variation in performance can be indicative of a reciprocal effect, with the consequence for the adoption of the cultivar to be used as the maternal or paternal parent (Rocha et al. 2014); however, it is based on visual verification of performance through graphical analysis, requiring a significance test for the reciprocal effect. These effects may be due to the nuclear genes (maternal effect) and cytoplasmic genes (non-maternal effect) (Barata et al. 2019). Easterly et al. (2020), who studied $650 \mathrm{~F}_{1}$ combinations of wheat, reported an insignificant reciprocal effect in grain yield. Pelegrin et al. (2020), who studied $F_{2}$ populations of wheat with a partial diallel crossing design $(5 \times 5)$, reported a significant reciprocal effect for the trait grain weight per plant.

\section{Jinks and Pooni methodology}

The probability of extracting superior lines was calculated using the method by Jinks and Pooni (1976) (Table 2). The probability ranged from 0.00 (Tbio Ponteiro/BRS 254) to 49.64 (CD 1303/Tbio Ponteiro). Six populations (CD 1303/BRS 254, CD 1303/Tbio Duque, CD 1303/Tbio Ponteiro, BRS 264/Tbio Aton, Tbio Ponteiro/Tbio Aton, and Tbio Sossego/CD 1303) recorded probabilities greater than $45 \%$. These populations stood out for the extraction of superior lines with productive potential. The Jinks and Pooni (1976) method has proven its efficiency in other studies involving grain crops, such as rice (Morais Júnior et al. 2015) and beans (Rocha et al. 2013).

Pimentel et al. (2013) highlighted that when estimates of genetic components are obtained through evaluations in individual plants, the results are biased due to the high volume of errors associated with negative genetic variance estimates being possible. Furthermore, errors associated with measurements on individual plants are inevitable as they are not homogeneous at the time of sampling, and each plant can interact exclusively with the environment (Westneat et al. 2015). In this context, techniques such as the REML/BLUP method that estimate the genetic values of individual plants and minimize tendencies should be adopted.

The REML/BLUP method stands out for its ability to provide the genetic value (BLUP) of each plant even under unbalanced conditions by assuming central estimates of genetic value, that is, normally distributed with the true genetic value being central, making it an unbiased predictor. Thus, selection between and within populations is allowed to increase the prediction success. REML, in turn, is translation-invariant, besides being iterative, providing estimates of non-negative variance components for restricting the parametric space, which is an unbiased method once a sufficient number of observations are used (Resende and Alves 2020). Thus, the REML/BLUP methodology is ideal for estimating genetic parameters and predicting genetic values. The genetic variance estimated in the present study did not present negative values (Table 2), that is, within the parametric space, differently from what occurs in contrast to the methodology by Jinks and Pooni (1976), based on phenotypic data using the least-squares technique. Previous studies have reported the superiority of biometric techniques based on the REML/BLUP methodology compared to those based on least squares, such as selection indexes (Entringer et al. 2016), diallel analysis (Laviola et al. 2018), and genetic diversity (Casagrande et al. 2020).

\section{Selection of superior plants}

The genotypic value (BLUP) of plants above the mean of six $F_{2}$ populations of tropical wheat selected by the method by Jinks and Pooni (1976) $(P>45 \%)$ are shown in Figures 2 and 3 . The mean of genetic values of the six selected populations was $12.81 \mathrm{~g} \mathrm{pl}^{-1}$ which was $30.05 \%$ more than the means of the other $\mathrm{F}_{2}$ populations and $87.83 \%$ more than the means of the parents. The CD 1303/Tbio Duque population had 55 plants with means higher than $12.81 \mathrm{~g} \mathrm{pl}^{-1}$, with the population with the highest number of individuals above the mean, followed by the CD 1303/Tbio Ponteiro population with 40 individuals with values above the mean. The other populations had 39 (CD 1303/BRS 254) and 31 (Tbio Ponteiro/Tbio Aton) individuals above the mean. Although the selection of segregating populations in the $\mathrm{F}_{2}$ generation should be treated sparingly because of previously reported heterosis effects on productivity (Bailey et al. 1980, Jiang et al. 2017), these populations have promising performances when analyzing the Jinks and Pooni probability (P\%) value together with their genotypic means. The greater number of selected populations in which the cultivar CD 1303 (four populations) participated as parents regardless of the large number of descendants selected in these populations are indications that this parent has a high number of favorable alleles for the grain yield trait; 
Table 2. Average genetic value per plant $\left(\mathrm{g} \mathrm{pl}^{-1}\right)$, genetic variance $\left(\hat{\sigma}_{d}^{2}\right)$, heritability $\left(h^{2}\right)$, $Z$ value for $\bar{L}=12.14 \mathrm{~g} \mathrm{pl}{ }^{-1}$ and their respective probabilities of extraction of superior lines $(P, \%)$, for the grain production trait per plant of tropical wheat $F_{2}$ populations

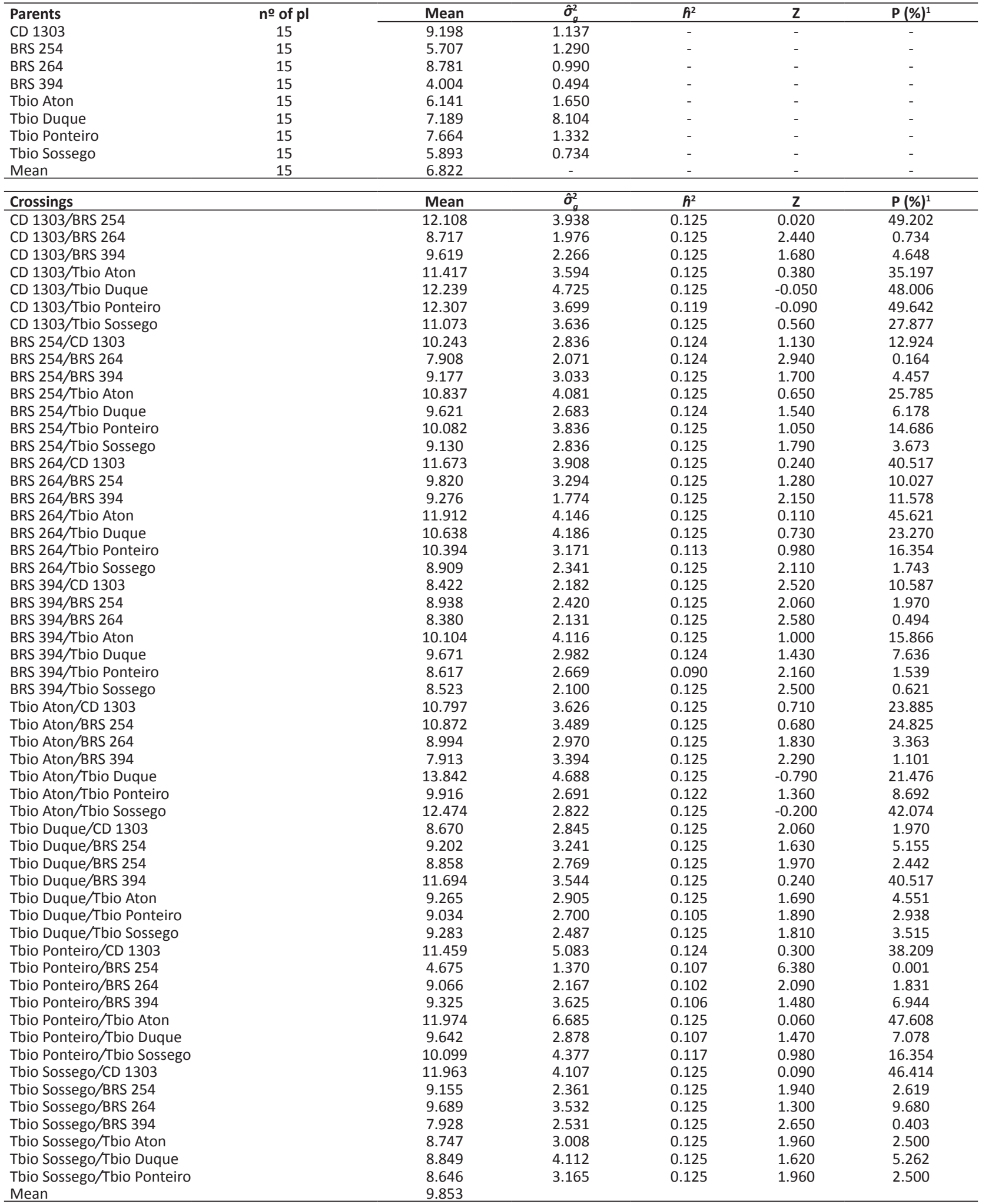

${ }^{1}$ highlighted probabilities: selected populations. 
A

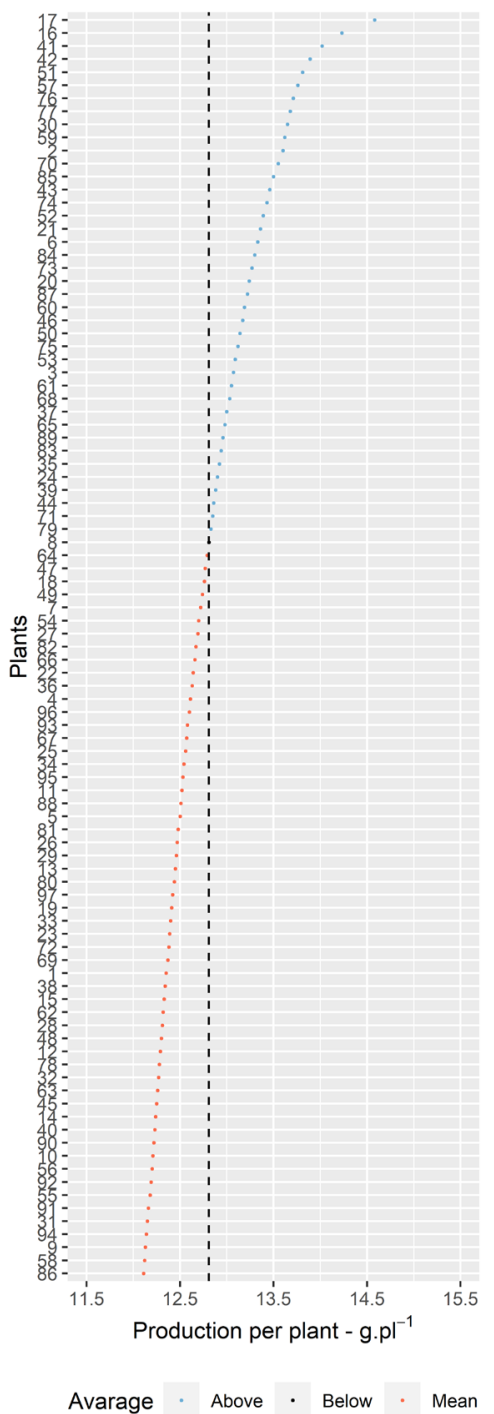

B

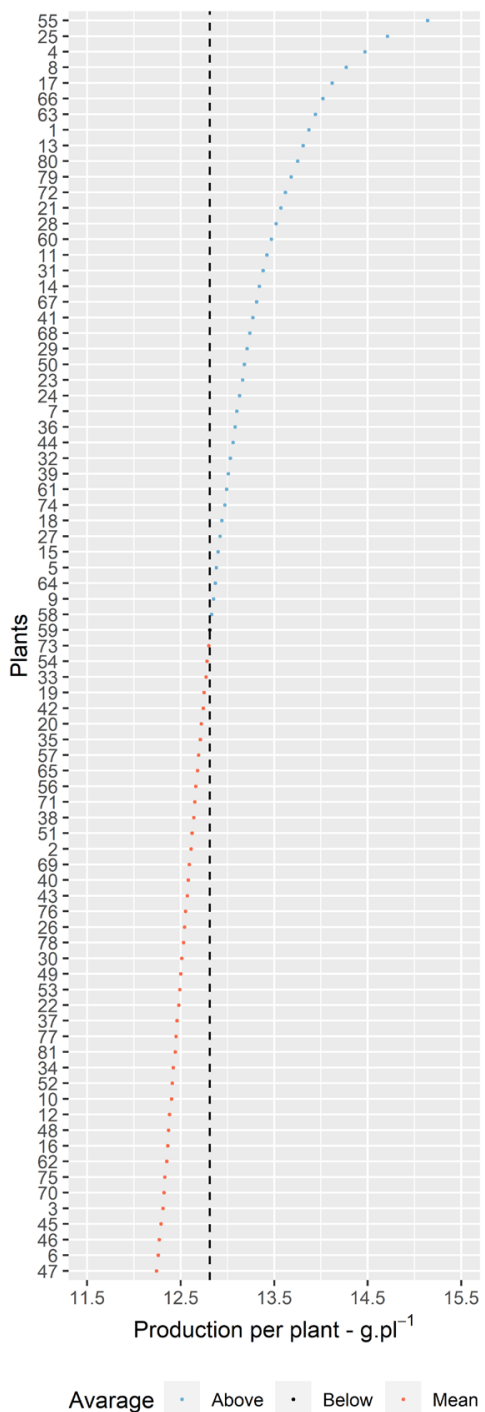

C $\quad$ CD 1303/Tbio Ponteiro

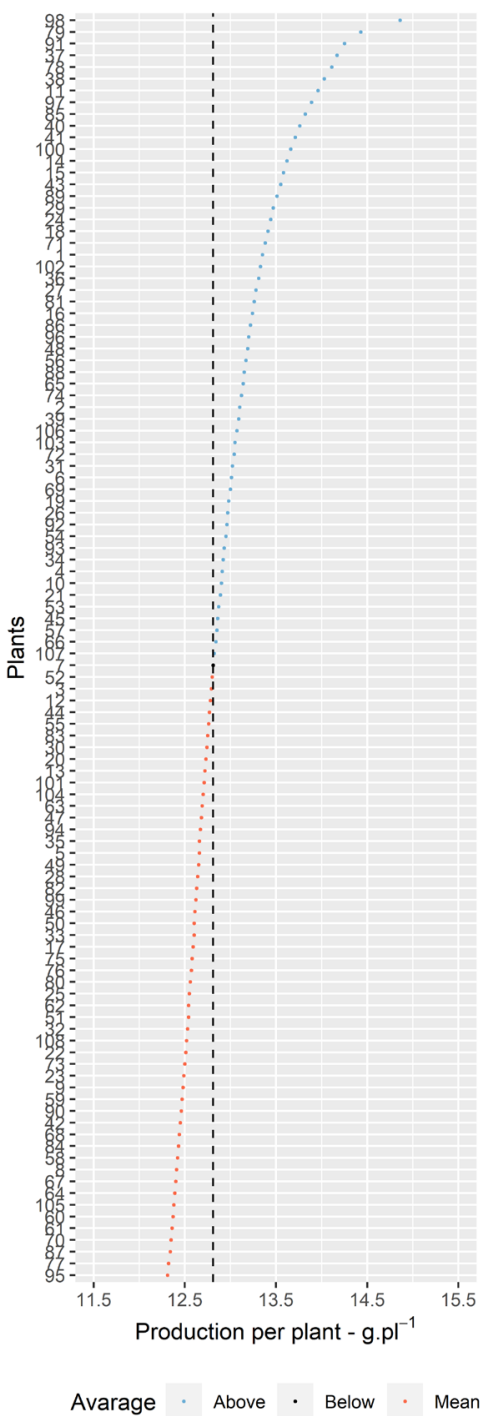

Figure 2. Genotypic value (BLUP) of plants above the mean of three $F_{2}$ populations of tropical wheat selected by the method of Jinks and Pooni (1976).

thus, lines from these plants have a high potential for use in tropical wheat breeding programs. For the selection of individuals based on the genetic value in this study, the individual BLUP is more reliable than the selection based on phenotypic values. This is because BLUP depends on the genetic merit of the population to predict the individual genetic value (Cowling 2013).

Using the REML/BLUP methodology proved to be efficient in generating genetic variances within the proposed parametric space with consequent reliable individual genetic effects (BLUPi) for the selection of wheat plants in the $F_{2}$ generation, considering that the individual evaluation of plants undergoes strong environmental influence, distorting the results of previous studies using least squares. Thus, the use of the methodology by Jinks and Pooni (1976) associated with the REML/BLUP methodology demonstrates the potential for use in improving wheat, intending to select superior individual plants in early generations. 
A

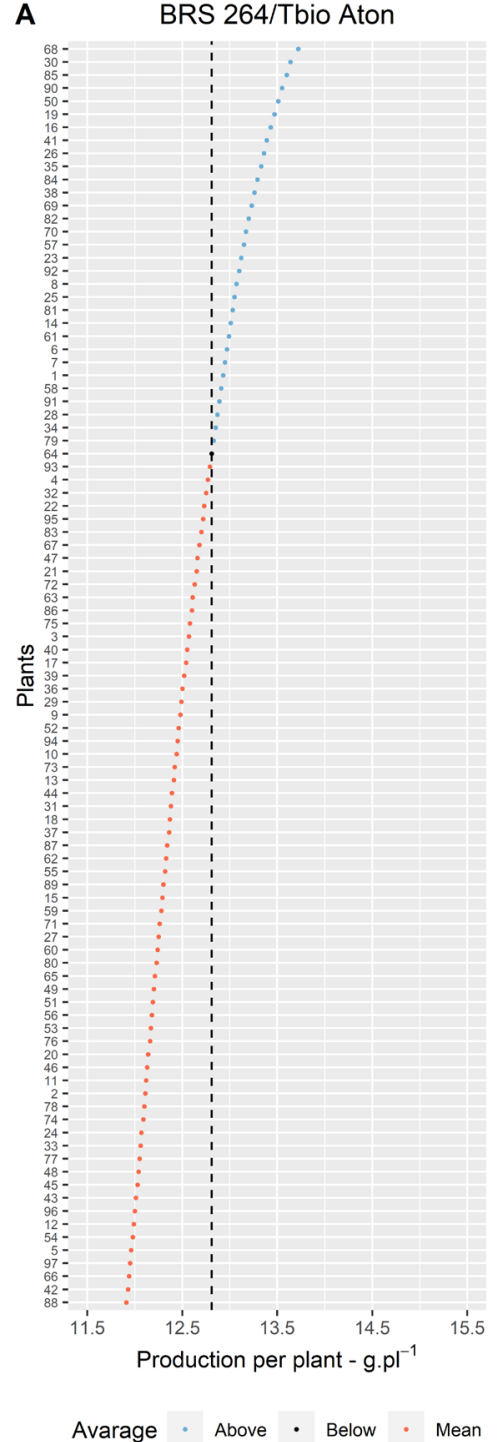

B

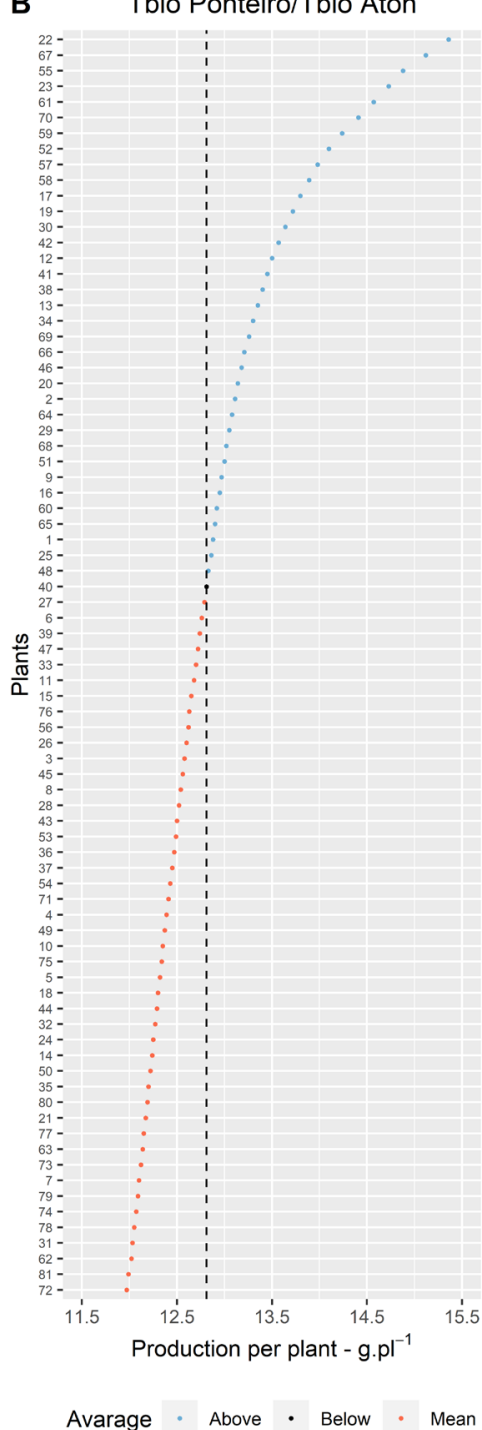

C Tbio Sossego/CD 1303

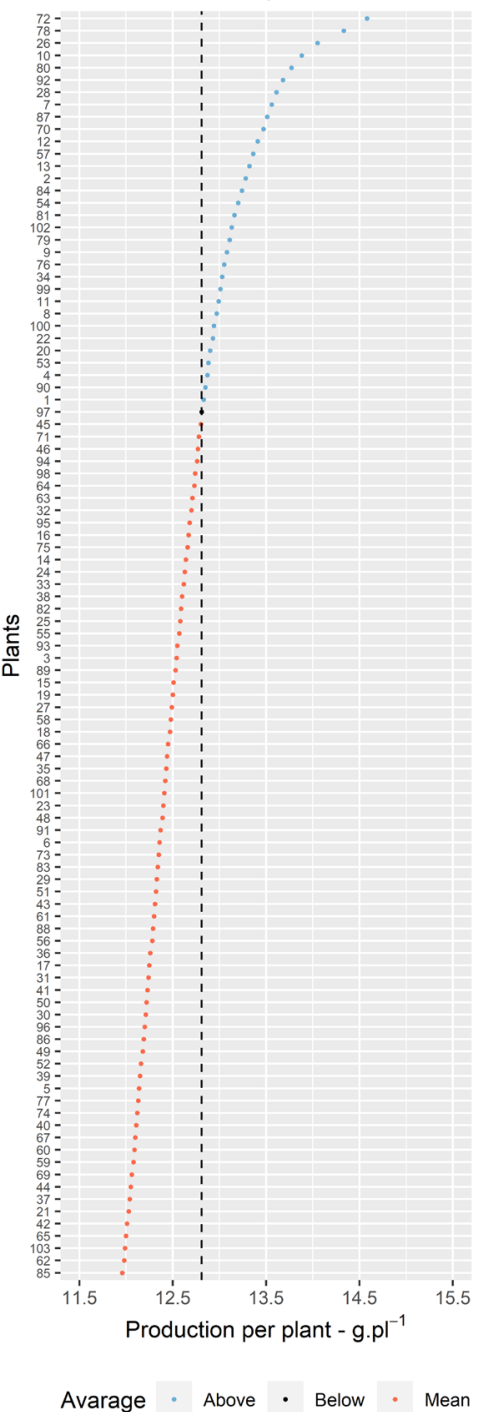

Figure 3. Genotypic value (BLUP) of plants above the mean of three $F_{2}$ populations of tropical wheat selected by the method of Jinks and Pooni (1976).

\section{CONCLUSIONS}

The method by Jinks and Pooni (1976), when using the genetic variance of REML with the individual genotypic value (BLUP), is an efficient alternative for selecting the most promising populations in tropical wheat.

The $F_{2}$ populations CD 1303/BRS 254, CD 1303/Tbio Duque, CD 1303/Tbio Ponteiro, BRS 264/Tbio Aton, Tbio Ponteiro/ Tbio Aton, and Tbio Sossego/CD 1303 have the potential to derive superior lines of tropical wheat.

\section{ACKNOWLEDGMENTS}

This study was financed in part by the Coordenação de Aperfeiçoamento de Pessoal de Nível Superior - Brasil (CAPES) - Finance Code 001. We would like to thank Conselho Nacional de Desenvolvimento Científico e (CNPq) and Fundação de Amparo à Pesquisa do Estado de Minas Gerais for the financial aid and scholarships granted. 


\section{REFERENCES}

Bailey TB, Qualset CO Jr and Cox DF (1980) Predicting heterosis in wheat. Crop Science 20: 339-342.

Barata NM, Scapim CA, Guedes TA, Janeiro V, Pinto RJB, Soto RIC and Kuki MC (2019) A new partial diallel model adapted to analyze reciprocal effects in grain yield of maize. Crop Breeding and Applied Biotechnology 19: 22-30.

Bowley AL (1920) Elements of statistics. Scribner, New York, 336p.

Casagrande CR, Mezzomo HC, Cruz CD, Borém A and Nardino M (2020) Choosing parent tropical wheat genotypes through genetic dissimilarity based on REML/BLUP. Crop Breeding and Applied Biotechnology 20: e329129316.

CONAB - Companhia Nacional de Abastecimento (2021) Acompanhamento da safra brasileira de grãos. Available at <https://www.conab.gov. $\mathrm{br}$ /ingo-agro/safras/graos/boletim-da-safra-de-graos $>$. Accessed on March 21, 2021.

Cowling WA (2013) A sustainable plant breeding. Plant Breeding 12: 1-9.

Easterly AC, Garst N, Belamkar V, Ibrahim AMH, Rudd JC, Sarazin JB and Baezinger PS (2020) Evaluation of hybrid wheat yield in Nebraska. Crop Science 60: 1210-1222.

Embrapa (2020) Informações técnicas para trigo e triticale: 13a Reunião da Comissão Brasileira de Pesquisa de Trigo e Triticale. Embrapa Trigo, Passo Fundo, 25p.

Entringer GG, Vettorazzi JCF, Santos EA, Pereira MG and Viana AP (2016) Genetic gain estimates and selection of S1 progenies based on selection indices and REML/BLUP in super sweet corn. Australian Journal of Crop Science 10: 411-417.

Fasahat P, Rajabi A, Rad JM and Derera J (2016) Principles and utilization of combining ability in plant breeding. Bimotetrics \& Biostatistics International Journal 4: 1-22.

Jiang Y, Schmidt R, ZHao Y and Reif JC (2017) A quantitative genetic framework highlights the role of epistatic effects for grain-yield heterosis in bread wheat. Nature Genetics 49: 1741-1746.

Jinks JL and Pooni HS (1976) Predicting the properties of recombinant inbreed lines derived single seed descent. Heredity 36: 243-266.

Laviola BG, Teodoro PE, Peixoto LA and Bhering LL (2018) Parental selection in diallel crosses of Jatropha curcas using mixed models. Acta Scientiarum. Agronomy 40: e35008.

Lima WF, Prete CEC, Ribeiro AS and Toledo JFF (2012) Resistência da soja à ferrugem-asiática avaliada pela análise da produtividade de grãos. Summa Phytopathology 38: 73-78.

McVetty PBE and Evans LE (1980) Breeding methodology in wheat. II. Productivity harvest index, and height measured on $\mathrm{F}_{2}$ spaced plants for yield selection in spring wheat. Crop Science 20: 587-589.
Morais Júnior OP, Melo PG, Morais OP, Castro AP, Breseghello F, Utumi M, Pereira JÁ, Wruck FJ and Filho JMC (2015) Genetic progress after cycles of upland rice recurrent selection. Scientia Agricola 72: 297-305.

Pasinato A, Cunha GR, Fontana DC, Monteiro JEBA, Nakai AM and Oliveira AF (2018) Potential área and limitations for the expansion of rainfed wheat in the Cerrado biome Central Brazil. Pesquisa Agropecuária Brasileira 54: 779-790.

Pelegrin AJ, Nardino M, Carvalho IR, Szareski VJ, Ferrari M, Conte GG, Oliveira AC, Souza VQ and Maia LC (2020) Combining ability as a criterion for wheat parents selection. Functional Plant Breeding Journal 2: 35-45.

Pereira JF, Cunha GR and Moresco ER (2019) Improved drought tolerance in wheat is required to unlock the production potential of the Brazilian Cerrado. Crop Breeding and Applied Biotechnology 19: 217-225.

Pimentel AJB, Guimarães JFR, Souza MA, Resende MDV, Moura LM, Rocha JRASCR and Ribeiro G (2010) Estimação de parâmetros genéticos e predição de valor genético aditivo de trigo utilizando modelos mistos. Pesquisa Agropecuária Brasileira 49: 882-890.

Pimentel AJB, Ribeiro G, Souza MA, Moura LM, Assis JC and Machado JC (2013) Comparação de métodos de seleção de genitores e populações segregantes aplicados ao melhoramento de trigo. Bragantia $\mathbf{7 2 :}$ 113-121.

R Core Team (2020) R: a language and environment for statistical computing. R Foundation for Statistical Computing, Vienna. Available at <https://www.r-project.org/>. Accessed on March 12, 2021.

Resende MDV (2016) Software Selegen-REML/BLUP: a useful tool for plant breeding. Crop Breeding and Applied Biotechnology 16: 330-339.

Resende MDV and Alves RS (2020) Linear, generalized, hierarchical, Bayesian and random regression mixed models in genetics/genomics in plant breeding. Functional Plant Breeding Journal 2: 1-31.

Rocha F, Stinghen JC, Gemeli MS, Coimbra JLM and Guidolin AF (2014) Análise dialélica como ferramenta na seleção de genitores em feijão. Ciência Agronômica 45: 74-81.

Rocha GS, Carneiro JES, Rezende Júnior LS, Pereira e Silva VM, Menezes Júnior JAN, Carneiro PCS and Cecon PR (2013) Effect of environments on the estimated genetic potential of segregating common bean populations. Crop Breeding and Applied Biotechnology 13: 241-248.

Silva FF, Viana JMS, Faria VR and Resende MDV (2013) Bayesian inference of mixed models in quantitative genetics of crop species. Theoretical and Applied Genetics 126: 1749-1761.

Westneat DF, Wright J and Dingemanse NJ (2015) The biology hidden inside residual within-individual phenotypic variation. Biological Reviews 90: 729-743.

Wickham H (2016) ggplot2: elegant graphics for data analysis. SpringerVerlag, New York, 213p.

(cc) EY This is an Open Access article distributed under the terms of the Creative Commons Attribution License, which permits unrestricted use, distribution, and reproduction in any medium, provided the original work is properly cited. 